Macedonian Pharmaceutical Bulletin, 66 (Suppl 1) 45 - 46 (2020)

Online ISSN 1857 - 8969

UDC: 613.25:615.874.2(497.7)

DOI: $10.33320 /$ maced.pharm.bull.2020.66.03.022

Short communication

\title{
Consumer perception of risk-benefit of weight loss supplements and building safety
}

\author{
Zoran Zhivikj ${ }^{1}$, Tanja Petreska Ivanovska ${ }^{1}$, Marija Karapandjova ${ }^{1}$, \\ Svetlana Kulevanova ${ }^{1}$, Marijana Lonchar Velkova ${ }^{2}$, Lidija Petrushevska-Tozi ${ }^{1}$ \\ ${ }^{I}$ Faculty of Pharmacy, Ss. Cyril and Methodius University, Mother Theresa 47, 1000, Skopje, N. Macedonia \\ ${ }^{2}$ Consumer Organization of North Macedonia, 50 th Division 10A, 1000, Skopje, N. Macedonia
}

\section{Introduction}

Obesity is a medical condition that occurs as a result of the accumulation of fat in the body and it is considered to be a major contributor to a variety of serious diseases. For obesity management, wide spectrum of weight loss dietary supplements is offered globally on the market. Five basic mechanisms of weight loss supplements are involved: controlling appetite, stimulating thermogenesis and lipid metabolism, inhibiting pancreatic lipase activity, preventing adipogenesis and promoting lipolysis (Kazemipoor et al., 2015).

The treatment of obesity using weight loss supplements at an optimum dosage should be safe and effective, but the data are limited in contrast to their popularity and advertisement. Moreover, among the issues that can affect safety, some of the supplements are adulterated with illegal addition of pharmaceutical substances (narcotics, stimulants, antidepressants, anorectics, laxatives and diuretics) or their analogues since unscrupulous producers can falsify these products to provide quick effects and to increase sales (Rocha et al., 2016). Finally, although adulterated with active pharmaceutical ingredients, most often they are mislabeled as being safe and natural (Khazan et al., 2014). In order to gain an insight in the consumer's experiences related to the use of weight loss dietary supplements in our country, we conduct a survey using an appropriate questionnaire in collaboration with the Consumer Organization of the Republic of North Macedonia.

\section{Materials and methods}

A questionnaire composed of 11 questions to objectively collect information about people's knowledge, beliefs, attitudes, and behavior related to the use of weight loss supplements was distributed using the following link: docs.google.com/forms/d/e/1FAIpQLSd3GOwJk17i otXeTCZGPw591dNx2-M_sUwcvUle0OpHXLyiPA /viewform?fbclid=IwAR1NJ0cXpcfMp19GjL4IRPB 7M5umdEIn0L_O7rEehjIzUT-2B9_SdXmIcWY, provided by Consumer Organization. Total of 242 consumers participated in the survey. Descriptive approach was applied to estimate specific parameters in a population (e.g. where the weight loss supplements were supplied from, frequency of weight loss supplement use, belief in their quality and safety and sufficiency of data provided to people, getting professional advice before consumption, notification of side effects during the use or afterwards).

\footnotetext{
*zzivic@ff.ukim.edu.mk
} 


\section{Results and discussions}

The survey confirmed the wide use of weight loss supplements (about $89 \%$ of the respondents). Only $16 \%$ of them looked for a professional opinion before taking a weight loss supplement. The majority of the people have been governed by the information electronically available or through advertising public media; while only $3 \%$ gathered professional help (18\% pharmacist's assistance and 9\% contacted nutritionists, health care providers and fitness instructors). About $70 \%$ of consumers reported no side health effects during the consumption of weight loss supplements, but they were doubtful regarding their quality. An internet sale was reported to be the most common way of supply, followed by pharmacies and healthy food stores. About $45 \%$ of people used weight loss supplements temporary, $35 \%$ once in the life and $20 \%$ continuously for several months. A great number of people (up to $85 \%$ ) considered insufficient the available information about efficacy and safety of weight food supplements. Beside the general belief that supplements, especially herbal ones are natural, harmless and effective means of obesity management, an internet sale of such products is not under the strict control and is not always required to pass safety tests before their advertisement and marketing (Khazan et al., 2014; Rocha et al., 2016). With the growing consumption and market globalization of dietary supplements, there is an increased need for accurate and effective screening and structural identification of adulterants or unknown analogues as well as specific regulatory preapproval requirements or safety assessments. Otherwise, consumers may be at great risk of many serious health problems. Even though many supplements do not contain any of the potentially deadly adulterants, many of them contain caffeine and/or green tea extract at such high concentrations that they can also be quite toxic (da Justa Neves and Caldas, 2017).
Despite the potentially serious health risks, very little is known about the prevalence or common adverse effects of dietary supplements adulterated by the illegal addition of pharmaceutical ingredients (Rocha et al., 2016). In our country there is also an increased demand and sale of weight loss dietary supplements, but a lack of data for their quality, efficiency and safety and the real economic profit as well. Hence, relevant authorities should enforce extensive clinical studies for long-term safety and efficacy at the same time strengthening the control tests including screen for contaminants and adulterants before marketing.

\section{Conclusions}

People should always seek a professional advice for proper use of weight loss supplements. Health care professionals are obligated to provide all necessary information and make people aware of related risks. Both, the research community and regulatory agencies are entailed to establish appropriate methods for detection of possible adulterations in weight loss supplements in order to protect the public health.

\section{References}

da Justa Neves, D.B., Caldas, E.D., 2017. Determination of caffeine and identification of undeclared substances in dietary supplements and caffeine dietary exposure assessment. Food Chem. Toxicol. 105, 194-202.

Kazemipoor, M., Cordell, G.A., Sarker, M.R., Jasimah, C., Radzi, W.M., Hajifaraji, M., Kiat, P.E., 2015. Alternative treatments for weight loss: safety/risks and effectiveness of anti-obesity medicinal plants. Int. J. Food Prop. 18, 1942-1963.

Khazan, M., Hedayati, M., Kobarfard, F., Askari, S., Azizi, F., 2014. Identification and determination of synthetic pharmaceuticals as adulteratants in eight common herbal weight loss supplements. Iran Red. Crescent Med. J. 16, e15344.

Rocha, T., Amaral, J.S., Oliveira, M.B.P.P., 2016. Adulteration of dietary supplements by the illegal addition of synthetic drugs: a review. Compr. Rev. Food Sci. Food Safety 15, 43-62. 